\title{
Effect of acid etching and aging on bond strength of a universal adhesive on dental enamel
}

\begin{abstract}
Mild self-etch one-step multi-mode universal adhesive shows a less favorable adhesion to enamel that is why enamel pre-etching with phosphoric acid gel is the way to achieve the best bonding. This paper evaluated the effect of enamel etching and sample aging of a universal adhesive system on microtensile bond strength ( $\mu$ TBS). Eleven human third molars were sectioned in half to obtain 22 proximal enamel surfaces. They were planned, polished and randomly assigned (subdivided samples) into 4 groups $(\mathrm{n}=11)$ according to the treatment (etched [Et], non-etched [no-Et]), and storage time (immediate [I] or after 12 months aging $[12 \mathrm{~m}])$ : EtI, Et $12 \mathrm{~m}$, no-EtI, no-Et12m. The etched specimens were conditioned with $37 \%$ phosphoric acid gel and for bonding, Scothbond Universal Adhesive [SBU] was used according to the manufacturer's instructions. Non-etched groups only received SBU. Next, a composite resin block (Filtek Z100, 3M ESPE) was incrementally built up. After storage in deionized water for 24 hours, the specimens were sectioned into beams $(1.0 \pm 0.2 \mathrm{~mm}$ area) and subjected to $\mu \mathrm{TBS}$ at a crosshead speed of $0.5 \mathrm{~mm} / \mathrm{sec}$. Data were submitted to two-criteria ANOVA $(\mathrm{p}<0.01)$ followed by the Tukey's post-test $(p<0.05)$. Fractured surfaces were analyzed for failure mode by digital optical microscopy (magnification of $100 \%$ ) and categorized according to the remaining structure, which were expressed as percentage for each group. Enamel etching increased $\mu$ TBS values after immediate traction. After 12 months, $\mu$ TBS values decreased significantly, with no statistical difference between the Et and no-Et groups. Phosphoric acid etching of enamel increased the immediate bond strength, which was significantly reduced after 12-months aging.
\end{abstract}

Keywords: acid etching, dental, dental enamel, dentin-bonding agents
Volume 10 Issue 5 - 2019

\author{
Barbara Vincenzi, Mariana Macedo Ribas, \\ Vera Lucia Schmitt, Fabiana Scarparo Naufel, \\ Kevelin Poliana Palma Rigo Thiesen, Maria \\ Daniela Basso de Souza \\ School of Dentistry, State University of Western Paraná \\ (UNIOESTE), Brazil
}
Correspondence: Maria Daniela Basso de Souza, School of Dentistry, State University of Western Paraná (UNIOESTE), Cascavel, PR, University Street, 2069 University Garden - ZIP Code 85819-110 - Cascavel -PR, Brazil, Emailmdanibs@gmail.com

Received: October 17, 2019 | Published: October 23, 2019
Abbreviations: $\mu$ TBS, microtensile bond strength; SBU, scothbond universal adhesive; SEUA, self-etch one-step multi-mode universal adhesive; $\mathrm{AD}$, adhesive in enamel; HEMA, 2-hydroxyethyl methacrylate

\section{Introduction}

The best bonding to enamel is achieved by selective etching of enamel margins [SE] (with phosphoric acid gel) prior the application of self-etch one-step multi-mode universal adhesive [SEUA]. ${ }^{1-11}$ When using the self-etch approach, the adhesion depends on the material formulation. Particularly for mild SEUA (e.g. Scotchbond Universal Adhesive (SBU)), systematic reviews showed a less favorable adhesion to enamel. ${ }^{12,13}$ In this line, despite the relevance to predict clinical outcomes, ${ }^{14-16}$ few in vitro studies about SBU have addressed microtensile bond strength $[\mu \mathrm{TBS}]$ to enamel under the influence of SE. ${ }^{2,5,6}$ Besides, the effect of storage water thermocycling time should be also highlighted. Reduced $\mu$ TBS values were observed when human enamel blocks underwent storage for 24-hour, ${ }^{2}$ maybe a short time for accurate measures failures. Longer time (12-month) studies (which should be encouraged in order to predict the clinical effectiveness of adhesives), ${ }^{17}$ do not definitively aver that question. ${ }^{6,11}$

In addition, study designs done up to 2015 were criticized in a systematic review and meta-analysis ${ }^{13}$ in respect of enamel evaluation. Medium risk of bias (for at least one of these: blinding of the examiner, description of coefficient of variation, sample size calculation) and or high heterogeneity was detected..$^{2-4}$
Thus, to add free bias risk evidences, the present study evaluated the effect of prior acid etching of enamel and longer time aging on microtensile bond strength of Scotchbond Universal Adhesive. The null hypothesis was that

a. The Acid etching of enamel

b. Aging did not affect the bond strength.

\section{Materials and methods}

The present study was approved by the Research Ethics Committee of the State University of Western Paraná (UNIOESTE) (CAAE 48197115.3.0000.0107). Eleven extracted unerupted third human molars were collected, cleaned and stored in a $0.1 \%$ thymol solution under refrigeration before the experiment. Next, the roots were removed.

\section{Sample calculation}

Sample size was calculated in terms of a minimum detectable difference in a mean BS (Mpa) of 0.62 (30 human teeth, 8 per group), using the same adhesive system with and without enamel acid etching. ${ }^{2}$ However, for predicting eventual losses, 11 samples (10 stick each, on average) were included.

\section{Specimen preparation}

The crown from each tooth was sectioned in the bucal-lingual direction using a 4 "x 0.012 " x 0.5 "diamond cutting disc (Erios Equipamentos Ltda - EPP, São Paulo, Brazil) mounted in a precision 
saw (Labcut 1010, Erios Equipamentos Ltda - EPP, São Paulo-SP, Brazil) at low speed to obtain 2 samples (22 in total). The enamel proximal surface of the fragments was planned and polished with sequential silicon carbide abrasive papers under water cooling until the 2000-grit ${ }^{2}$ (Figure 1). The samples were randomly assigned into 2 groups ( $\mathrm{n}=11$ ) according to the enamel treatment: etched (Et) and nonetched (no-Et). The procedure was performed with $37 \%$ phosphoric acid gel (Condac 37; FGM, Joinville, Brazil) for $15 \mathrm{~s}$, rinsed and gently air dried. For the bonding procedure, SBU was actively applied with a microbrush (20s), air dried (5s) and light cured for $10 \mathrm{~s}$ using a Valo Curing Light with power density of $1000 \mathrm{~mW} / \mathrm{cm}^{2}$ (Ultradent Products, INC., South Jordan, USA). The no-Et groups received only the adhesive system. Next, a composite resin block (Filtek Z100, 3M ESPE, St Paul, MN, USA) was incrementally built up to a thickness of approx. $4 \mathrm{~mm}$. The compositions and manufactures of the materials are shown in Table 1.

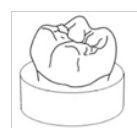

A

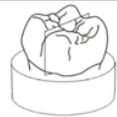

B

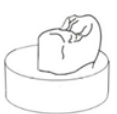

C

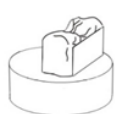

D

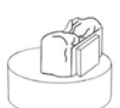

$\mathrm{E}$

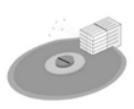

$\mathrm{F}$

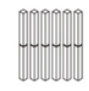

G
Figure I Schematic representation of the preparation of the specimens for the microtensile test. From a healthy tooth $(A)$, sections were made in the $V L$ direction $(B, C)$. A flat enamel surface (D) was obtained, for which the restoration of composite resin was carried out according to the experimental groups $(E)$. After serial cuts $(F)$, specimens were shaped like a toothpick $(G)$.

Table I Composition and manufactures of used materials

\begin{tabular}{ll}
\hline Materials, manufacture & Composition \\
\hline & $\begin{array}{l}\text { Adhesive: I0-MDP, phosphate monomer, } \\
\text { dimetacrylate }\end{array}$ \\
$\begin{array}{l}\text { Scotchbond Universal } \\
\text { Adhesive, 3M ESPE, St Paul, } \\
\text { MN, USA }\end{array}$ & $\begin{array}{l}\text { resins, 2-hydroxyethyl methacrylate (HEMA), } \\
\text { methacrylate-modified polyalkenoic acid } \\
\text { copolymer, filler, ethanol, water, initiators, } \\
\text { silane }\end{array}$
\end{tabular}

Silane treated ceramic,

Triethylene glycol dimethacrylate (TEGDMA),

ZI00, 3M ESPE, St Paul, MN, USA

Bisphenol A diglycidyl A ether dimethacrylate (BISGMA),

\section{2-Benzotriazolyl-4-methylpphenol}

Condac 37/ FGM, Joinville, Phosphoric acid at 37\%, thickener, pigment SC, Brazil

and deionized water.

\section{Microtensile bond strength ( $\mu$ TBS)}

After 24 hours of storage in deionized water $\left(37^{\circ} \mathrm{C}\right)$, the samples were longitudinally sectioned in both the ' $\mathrm{x}$ ' and ' $\mathrm{y}$ ' directions across the adhesive interface using a low-speed diamond saw in a precision sectioning machine to obtain sticks $\left(1.0 \mathrm{~mm} \pm 0.2 \mathrm{~mm}^{2} ; 10\right.$ per sample on average) (Figure 1). As pre-testing failures, there were/was 0 debonded specimens during the sectioning process. The sticks were randomly subdivided into 2 groups $(\mathrm{n}=11)$ according to the storage time: immediate (I) or after 12-month. As aging failures, there were/ was 0 de-bonded specimens during the aging process. At the end, four groups $(n=11)$ were determined: EtI, Et12m, no-EtI, no-Et12m. The $\mu$ TBS test was done by operator who did not prepared specimens. Each stick was attached to a testing jig with cyanocrylate adhesive (Super Bonder Gel, Loctite, Henkel Ltda, São Paulo-SP, Brazil) and subjected to tension in a universal testing machine (Emic-Instron, São José dos Pinhais-PR, Brazil) at a crosshead speed of $0.5 \mathrm{~mm} /$ sec. The results of $\mu$ TBS values were expressed in MPa. Statistical analysis was performed using the SigmaPlot 12.0 software (Systat Software Inc., San Jose, California, USA) at a significance level of $5 \%$ considering the etching and aging procedures as variation factors. The mean $\mu$ TBS values among the specimens within each group were used for the statistical analysis. The variable passed normality and homogeneity tests (Shapiro-Wilk/Kolmogorov-Smirnov) and was submitted to two-way ANOVA $(\mathrm{p}<0.01)$ followed by the Tukey's post-hoc test. The fractured surfaces of the sticks were then submitted to a failure mode analysis by digital optical microscopy (Dino-Lite) (magnification $2 \mathrm{x}$ ) and categorized according to the predominant remaining structure: adhesive in enamel (AD); cohesive in enamel (CE); cohesive in resin (CR); or mixed: failure between adhesive/ resin $[\mathrm{M}-\mathrm{AR}]$ or among adhesive/resin/enamel [M-ARE]). Failure modes were expressed as percentage for each group.

\section{Results}

The mean values of $\mu$ TBS are shown in Table 2 . The highest $\mu$ TBS value was observed for the EtI group (52.68 \pm 13.85$)$, followed by the no-EtI $(37.24 \pm 16.91)$, no-Et12m $(20.28 \pm 3.85)$ and Et12m $(19.28 \pm 5.27)$ groups. There was an influence of time $(\mathrm{F}=57.224$, $\mathrm{p}$ $<0.001)$ and treatment $(\mathrm{F}=4.797, \mathrm{p}=0.034)$ factors with significant interaction between them $(\mathrm{p}=0.02)$. The enamel acid etching promoted a significant increase of $\mu$ TBS values when sticks were submitted to immediate traction testing. However, after aging for 12 months, the $\mu$ TBS value decreased significantly, with no statistical difference between the etched and non-etched groups.

Table 2 Bond strength values ( $\mathrm{MPa}$ ) of etched and non-etched enamel (Et and no-Et, respectively) obtained by traction test immediately or after 12 months aging

\begin{tabular}{|c|c|c|c|}
\hline & & \multicolumn{2}{|l|}{ Treatment } \\
\hline & & Et & no-Et \\
\hline & Immediate & $52.68(13.85)^{\mathrm{Aa}}$ & $37.24(16.91)^{\mathrm{Ba}}$ \\
\hline Time & I2-months & $19, .28(5.27)^{A b}$ & $20.08(3.85)^{A b}$ \\
\hline
\end{tabular}

Mean $(d p), n=I I$. Superscript capital letters indicate significant difference between the means by line. Superscript lower-case letters indicate significant difference between the means by column. Two-way ANOVA and Tukey's test $(p<0.05)$.

The AD, M-AR (the more prevalent one) and CR were the identified failure modes, whose distributions are shown in Figure 2. For the noEtI group, the M-AR failure had the highest percentage followed by the $\mathrm{AD}$, whereas the $12 \mathrm{~m}$ aging (no-Et $12 \mathrm{~m}$ group) promoted reduction in the percentage of M-AR (51\%) and an increase in AD (49\%) failures. For the EtI group, the M-AR showed the highest percentage followed by the C-RC (37\%), and AD (6.5\%) failures. The 12-month aging (Et12m group) reduced the percentage of C-RC $(6.7 \%)$ and increased the M-AR (58.3\%) and AD (35\%) failures. Representative images of each failure mode are shown in Figure 3. 


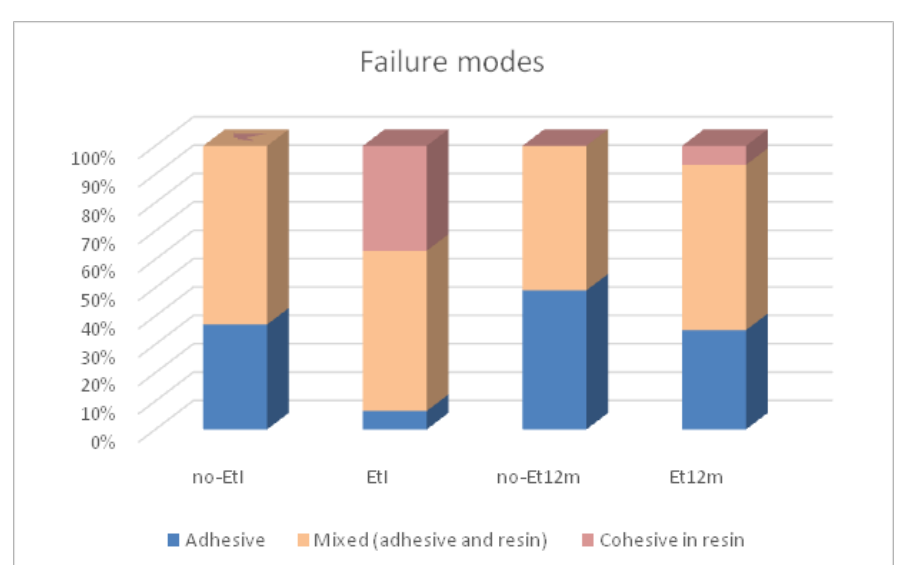

Figure 2 Failure modes.

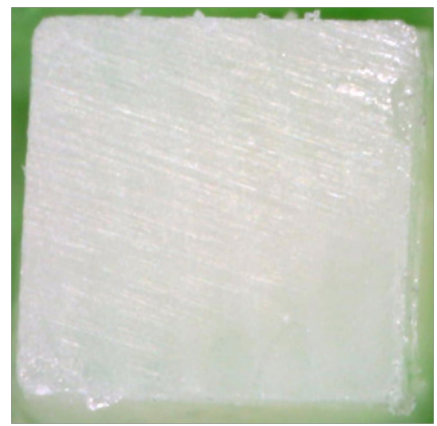

(A)

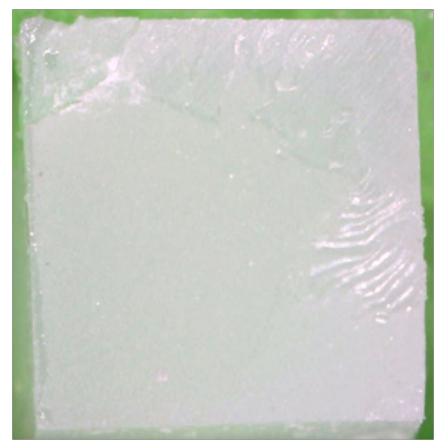

(B)

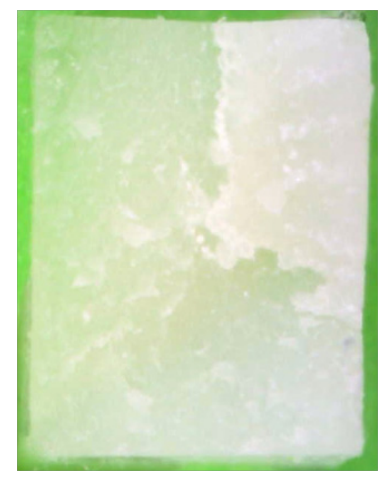

(C)

Figure 3 Representative images of the failure modes. (A) adhesive, (B) mixed and $(\mathrm{C})$ cohesive.

\section{Discussion}

The present study focused on the question: would pre-etching of enamel and aging decrease the adhesion durability when using SBU? To meet this goal, the guidance for the $\mu \mathrm{TBS}$ tests was strictly carried out (specimen preparation, optimal polymerization, storage and thermocycling). To reduce the regional and tooth variability, 10 sticks per tooth (central region) were used. ${ }^{18}$ The overall results reject the both null hypothesis: the bond strength was increased by etching and reduced by 12-month aging.

SBU used in a self-etch approach is a challenging task to achieve composite resins restorations with satisfactory clinical aspect (e.g. marginal discoloration) and good retention rates. The lower $\mu$ TBS value of no-Et groups (than that of Et-groups) suggests SE approach was better than the self-etch one (for immediately test), showed by the almost 2-fold M-AR (63\%) failure compared to the AD (37\%) one (12-month aging increased it to 51\%). Although no other image analysis except digital optical microscopy was made, we presume the SBU acidic profile produced a shallower etch-pits and disfavored the micromechanical interlocking (by resin tags penetration), $, 1,5,19,20$ even with the outer enamel surface removal (more mineralized) by planning/polishing.

The adhesive formulation could also explain the lower bond strength observed in the no-Et groups. It is known that micromorphology of etched enamel depends on its aggressiveness which is directly related to acidity, ${ }^{21}$ observed by ultra morphology analysis too. ${ }^{14}$ So, the lower $\mathrm{pH}$ (acidic) the more enamel demineralization. ${ }^{17}$ In this line, SBU (mild, $\mathrm{pH} \approx 2$ ) was probably weak to promote a stronger hybrid layer on enamel by the penetration of adhesive resins into porous enamel, compared to that of phosphoric acid etching.

The interplay among 10-MDP, 2-hydroxyethyl methacrylate (HEMA) and Vitrebond copolymer (VCP) (a polyalkenoic acid copolymer) might explain the lower bond strength for no-Et groups as well the reduction in Et12m group. In fact, enamel bond strength of MDP-based all-in-one adhesives strongly contributes to the demineralization efficacy by the incorporation of MDP. ${ }^{15}$ This last, by chemical reaction to $\mathrm{Ca}$ (released upon the partial Hap dissolution), forms a better and water-stable enamel-adhesive interface (consisted of nano-layered 10-MDP-Ca salt structures) which favor the adhesive stability bond strength. ${ }^{19,22}$ However, HEMA containing adhesives shows a slower production rate of that salt in the enamel (compared with the HEMA-free). ${ }^{15}$ On the other hand, VCP (also chemical bonds to $\mathrm{Ca}$ of Hap) ${ }^{22,23}$ competes with the other two. Altogether, we presume those nano-layered structures were compromised, ${ }^{12,15,16}$ impairing the resistance to biodegradation and longevity of the bond strength, ${ }^{12,24}$ mainly after 12 -month aging. The bond strength dropped $54 \%$ and $36.5 \%$ for no-Et and Et groups, respectively. As any aging process may lower the long-term bonding effectiveness, ${ }^{6,11,17}$ we assume 12-month aging was probably enough to damage the stability and dissolution rate of the nano-layered 10-MDP-Ca, increasing interfacial leakage and compromising the adhesive interface. ${ }^{23,19}$ However, it is a supposition because we did not assess neither microleakage nor nano-leakage.

In respect of $\mathrm{SE}$, the comparison between the Et and no-Et groups clearly shows that $37 \%$ phosphoric acid gel significantly increased the $\mu$ TBS values (for immediately tested specimens). ${ }^{2,3,8,11,12}$ However, while Et12month group $\mu$ TBS values was 2.7 times lower compared to that immediately aged, other study reported about 1.5 times lower. ${ }^{6}$ This difference may be due to the methodological variation 
(phosphoric acid gel concentration, stick size, crosshead speed) So, we presume deep etch-pits on enamel produced by SE favored monomers infiltration, improved the micromechanical interlocking (by resin tags penetration) and created a strong stable hybrid layer on enamel prisms. ${ }^{12}$ That interface enamel-adhesive quality might have been responsible to enhance bond strength ${ }^{1,5,19,21}$ and the lower frequency of $\mathrm{AD}$ failures illustrates it. The cohesive (C-RC) failure shows the $\mu$ TBS values were high enough for composite resin to be lost instead of the adhesive. ${ }^{6}$ Thus, the adhesive layer might have been quite different from that of self-etching approach, given the etching pattern ranging from absent to moderate in the last case. ${ }^{25}$ It should be highlighted the present results can only be applied to another SEUA with the same formulation because bond strength to enamel can vary according to brands and compositions. ${ }^{6,21}$

Drawing a parallel between in vitro and clinical studies the bond strength results is worthwhile. Despite long-term thermocycling led a reduction on $\mu$ TBS values for Et and no-Et groups (statistically similar each other), the clinical one shows a satisfactory long-term retention when SBU was applied in the self-etching mode for restorations class $\mathrm{I}^{26}$ and $\mathrm{V}^{25,27}$ (the most critical). ${ }^{27}$ Weighing pros and cons (longer clinical time), several studies ${ }^{24,29-32}$ endorses SE to enhance the restoration longevity (reduce marginal defects ${ }^{33}$ and discoloration, ${ }^{27,31,33}$ which needs to be evaluated for class II restorations.

\section{Conclusion}

Phosphoric acid etching of enamel increased the immediate bond strength, which was significantly reduced after 12-months of aging when using Scothbond Universal Adhesive.

\section{Funding details}

Financial support: Coordination for the Improvement of Higher Education Personnel - Capes.

\section{Acknowledgments}

None.

\section{Conflicts of interest}

The authors declare that there is no conflict of interest.

\section{References}

1. Cuevas-Suárez CE, da Rosa WLO, Lund RG, et al. Bonding performance of universal adhesives: an updated systematic review and meta-analysis. $J$ Adhes Dent. 2019;21(1):7-26.

2. de Goes MF, Shinohara MS, Freitas MS. Performance of a new one-step multi-mode adhesive on etched vs non-etched enamel on bond strength and interfacial morphology. J Adhes Dent. 2014;16(3):243-250.

3. Goracci C, Rengo C, Eusepi L, et al. Influence of selective enamel etching on the bonding effectiveness of a new "all-in-one" adhesive. Am J Dent. 2013;26(2):99-104.

4. Hanabusa M, Mine A, Kuboki T, et al. Bonding effectiveness of a new 'multi-mode' adhesive to enamel and dentine. J Dent. 2012;40(6):475-484.

5. Hoshika S, Kameyama A, Suyama Y, et al. GPDM- and 10-MDP-based self-etch adhesives bonded to bur-cut and uncut enamel - "immediate" and "aged" $\mu$ TBS. J Adhes Dent. 2018;20(2):113-120.

6. Makishi P, André CB, Ayres A, et al. Effect of storage time on bond strength and nanoleakage expression of universal adhesives bonded to dentin and etched enamel. Oper Dent. 2016;41(3):305-317.
7. Perdigão J, Kose C, Mena-Serrano AP, De Paula EA, et al. A new universal simplified adhesive: 18-month clinical evaluation. Oper Dent. 2014;39(2):113-127.

8. Sato T, Takagaki T, Matsui N, et al. Morphological evaluation of the adhesive/enamel interfaces of two-step self-etching adhesives and multimode one-bottle self-etching adhesives. $J$ Adhes Dent. 2016;18(3):223-229.

9. Suzuki S, Takamizawa T, Imai A, et al. Bond durability of universal adhesive to bovine enamel using self-etch mode. Clin Oral Investig. 2018;22(3):1113-1122.

10. Suzuki T, Takamizawa T, Barkmeier WW, et al. Influence of etching mode on enamel bond durability of universal adhesive systems. Oper Dent. 2016;41(5):520-530.

11. Vermelho PM, Reis AF, Ambrosano GMB, et al. Adhesion of multimode adhesives to enamel and dentin after one year of water storage. Clin Oral Investig. 2017;21(5):1707-1715.

12. Carrilho E, Cardoso M, Marques Ferreira M, et al. 10-MDP based dental adhesives: adhesive interface characterization and adhesive stability-a systematic review. Materials (Basel). 2019;12(5):pii:E790.

13. Rosa WL, Piva E, Silva AF. Bond strength of universal adhesives: A systematic review and meta-analysis. J Dent. 2015;43(7):765-776.

14. De Munck J, Van Landuyt K, Peumans M, et al. A critical review of the durability of adhesion to tooth tissue: methods and results. J Dent Res. 2005a;84(2):118-132.

15. Fujita NK, Nikaido T, Arita A, et al. Demineralization capacity of commercial 10-methacryloyloxydecyl dihydrogen phosphate-based allin-one adhesive. Dent Mater. 2018;34(10):1555-1565.

16. Fujita-Nakajima K, Nikaido T, Francis Burrow M, et al. Effect of the demineralisation efficacy of MDP utilized on the bonding performance of MDP-based all-in-one adhesives. J Dent. 2018;77:59-65.

17. Van Meerbeek B, Peumans M, PoitevinA, et al. Relationship between bondstrength tests and clinical outcomes. Dent Mater. 2010;26(2):e100-121.

18. Armstrong S, Breschi L, Özcanc M, et al. Academy of Dental Materials guidance on in vitro testing of dental composite bonding effectiveness to dentin/enamel using micro-tensile bond strength ( $\mu$ TBS) approach. Dent Mater. 2017;33(2):133-143.

19. Van Landuyt KL, Kanumilli P, De Munck J, et al. Bond strength of a mild self-etch adhesive with and without prior acid-etching. J Dent. 2006;34(1):77-85.

20. Van Meerbeek B, Yoshihara K, Yoshida Y, et al. State of the art of selfetch adhesives. Dent Mater. 2011;27(1):17-28.

21. Tay FR, Pashley DH. Aggressiveness of contemporary self-etching adhesives. I: Depth of penetration beyond dentin smear layers. Dent Mater. 2001;17(4):296-308.

22. Mitra SB, Lee CY, Bui HT, et al. Long-term adhesion and mechanism of bonding of a paste-liquid resin-modified glass-ionomer. Dent Mater. 2009;25(4):459-466.

23. Muñoz M A, Luque-Martinez I, Malaquias $P$, et al. In vitro longevity of bonding properties of universal adhesives to dentin. Oper Dent. 2015;40(3):282-292.

24. Yoshida Y, Yoshihara K, Nagaoka N, et al. Self-assembled nano-layering at the adhesive interface. J Dent Res. 2012;91(4):376-381.

25. Perdigão J, Geraldeli S. Bonding characteristics of self-etching adhesives to intact versus prepared enamel. J Esthet Restor Dent. 2013;15(1):32-41; discussion 42 .

26. Favarão J, Zanini MM, Sinhorseti MAC, et al. Immediate and 6-month 
bond strengths of different adhesives in the oral environment. $J$ Adhes Dent. 2017;18(6):475-481

27. Loguercio AD, de Paula EA, Hass V, et al. A new universal simplified adhesive: 36-Month randomized double-blind clinical trial. J Dent. 2015;43(9):1083-1092.

28. De Munck J, Vargas M, Iracki J, et al. One-day bonding effectiveness of new self-etch adhesives to bur-cut enamel and dentin. Oper Dent. 2005b;30(1):39-49.

29. Fukegawa D, Hayakawa S, Yoshida Y, et al. Chemical interaction of phosphoric acid ester with hydroxyapatite. $J$ Dent Res. 2006;85(10):941-944.

30. Oz FD, Ergin E, Canatan S. Twenty-four-month clinical performance of different universal adhesives in etch-and-rinse, selective etching and selfetch application modes in NCCL-a randomized controlled clinical trial. $J$ Appl Oral Sci. 2019;27:e20180358.

31. Schroeder M, Correa IC, Bauer J, et al. Influence of adhesive strategy on clinical parameters in cervical restorations: A systematic review and meta-analysis. J Dent. 2017;62:36-53.

32. Yoshihara K, Yoshida Y, Nagaoka N, et al. Nanocontrolled molecular interaction at adhesive interfaces for hard tissue reconstruction. Acta Biomater. 2010;6(9):3573-3582.

33. Qin W Lei L, Huang QT, Wang L, et al. Clinical effectiveness of selfetching adhesives with or without selective enamel etching in noncarious cervical lesions: A systematic review. J Dent Sci. 2014;9(4):303-312. 